\title{
Precision of the Residual Stress determined by X-ray Diffraction: Summery and Limits
}

\author{
Eckehard Mueller ${ }^{1}$ \\ ${ }^{1}$ Bochum University of Applied Sciences, Department of Mechatronics and Mechanical Engineering, D-44801 Bochum, \\ Germany and Steinbeis-Transfercenter for Spring Technologies, Component Behaviour and Process, D-58638 Iserlohn, \\ Germany
}

\begin{abstract}
Today components specially for passenger cars are weight optimized. Often it is done by mechanical surface treatments. Therefore, the amount of compressive residual stress induced by the treatment must be known. The measurement is very often done by $\mathrm{x}$-ray diffraction. But how precise can you determine (and not directly measured) the amount? A big question is the calibration of the equipment. A specimen must be designed and calibrated by round robin test, because no measurement standard is available.
\end{abstract}

\section{Introduction}

The demands of the automotive industry are still increasing. In this scenario also the accuracy of measurements should be increased. Mostly the focus is on the statically error. The systematic error is often neglected. This situation is given by determining residual stresses by x-ray diffraction.

\section{Determining Residual Stresses}

\subsection{Basics}

Residual stress via x-ray diffraction can only be determined. The primary task is to measure the atomic distance e. g. in the steel components. With the help of the Young Module E and Poisson ratio $v$ the residual stress is calculated.

The basic method is called Bragg reflection. A detailed description of the whole method to determine residual stresses you find in different literature: [1;2;3]. A brief summary is given here. X-rays with the wavelength $\lambda$ are sent under certain angles $\Psi$ to the surface and the reflection angle $\theta$ with the maximum intensity is determined, because the x-ray has constructive interference. With the help of the formula:

$$
\lambda=2 d \sin \theta
$$

the spacing $d$ of the atomic layers were measured. The angles $\Psi$ is responsible which the orientation of the layers is measured and must also be taken in considerations. Out of this data the residual stress is calculated. Two different methods $\left(\sin ^{2} \Psi-2 \theta\right.$-method [3] and $\cos \alpha$-method [4]) are common. Both methods are compatible and here it is not important difference, which method is used $[5 ; 6]$. A very new equipment is shown in figure 1.

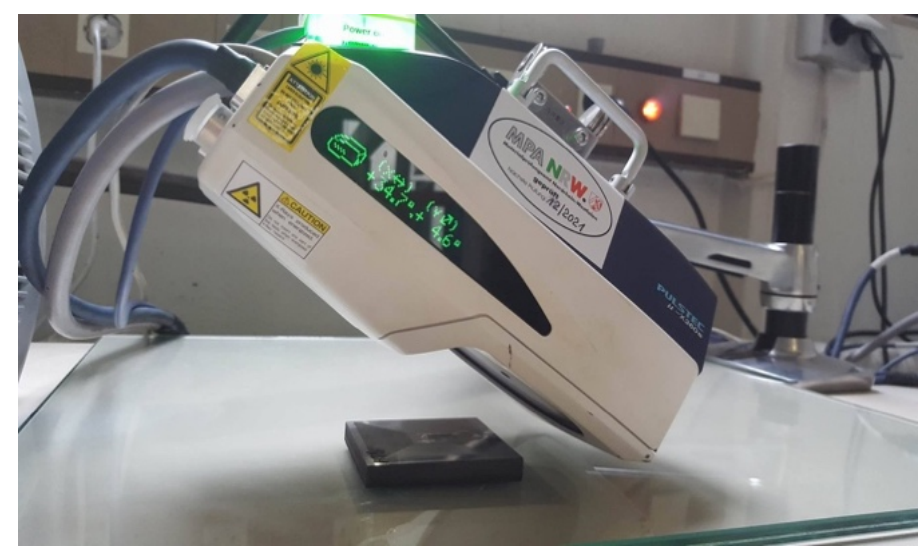

Fig. 1. a very modern $x$-ray-equipment

\footnotetext{
* Corresponding author: eckehard.mueller@hs-bochum.de
} 


\subsection{Measurement Errors}

\subsubsection{Introduction}

Every physical measurement has at least two errors: a statistical (or reading) error and a systematic error, which depends out of the equipment. Both errors will be shortly discussed in the following section.

\subsubsection{Statistical Error}

Measuring with more angles $\Psi$ for the $\sin ^{2} \Psi-2 \theta$-method or to measure several times at both method the statistical error can be reduce. Today this kind of error can be reduced with some efforts in the range of $1 \%$.

\subsubsection{Systematic Error}

The systematic error is based on two facts:

1. Surface error: The roughness may reduce the result of the compressive residual stress up to $25 \%$ for shot peened surfaces $[7 ; 8]$.

2. Equipment error: The main systematic error is the equipment error. The whole $\mathrm{x}$-ray diffractometer must be adjusted. That means the way of the x-rays through apertures to the material must be in a straight line and must correspond with the detection equipment. Minimal deviations can give results, which show more and less residual stresses. The author can see this several times, because he has access to five diffractometers of the same type.

No equipment is available to gauge such a machine like the International Prototype Metre. The only possibility is to organize round robin tests to optimize the accuracy, which is described in the next chapter.

\section{Calibration Sample for X-ray diffractometers}

\subsection{Introduction}

The long-term stability of an x-ray diffractometer can be monitored by a sample, which has high residual stresses. If the sample is stored at normal constant room temperature and no surface corrosion is possible, it can be used over decades. This situation is unsatisfied, because you do not know the systematic deviation of the machine (biased results).

\subsection{Round Robin Tests}

\subsubsection{General Demands}

Round robin tests are effective if you have lots of members to get a smaller error of the mean value, which is calculated. The other hand is to have a long-term stability of the sample if it is handled under adequate conditions. The shorter the experiment last the better it is, but the execution time can be more than a year. A first report was given on the International Conference on Residual Stresses [9].

\subsubsection{Overview of some Round Robin Test}

The last 10 years round robin tests concerning determine of residual stress by x-ray diffraction were made, is listed in table 1 . This listing may not complete- There might be some other test, which are not available by the author.

The test with the round material shows that the achieved value has a big dependence concerning the diameter of the $\mathrm{x}$-ray spot. Today this problem is documented in DIN EN 15305 [10] and a limit of the maximum spot diameter in relation the rod diameter of $20 \%$ is given for the $\sin ^{2} \psi-2 \theta$-method.

Table 1. List of Round Robin Test

\begin{tabular}{|l|l|l|l|l|l|}
\hline Nr. & year & sample(s) & mean value & Organizer (company, name) & reference \\
\hline 1 & $2006-2009$ & flat & $-350 \mathrm{MPa}$ & GKN, Mr. Lietzau & {$[11]$} \\
\hline 2 & $2006-2011$ & flat/round & $-800 \mathrm{MP}$ & Rigaku, Mr. Yokohama & {$[12]$} \\
\hline 3 & 2013 & round & $-650 \mathrm{MPa}$ & VDFI, Prof. Mueller & {$[13]$} \\
\hline 4 & $2012-2014$ & flat & $+550 /-1120 \mathrm{MPa}$ & GKN, Mr. Lietzau & {$[14]$} \\
\hline
\end{tabular}


The last round robin test $(\mathrm{Nr} .4)$ is one of the best tests which has been made, because the residual stress value is far away from zero both tensile and compressive residual stresses. Around 30 participants joined the test. The sample for the compressive residual stress is described now. It has residual stresses, which are stable over many years. The author tested equivalent sample over many years in his lab.

The demand of a high stress value can be realized by using material with high tensile strength. As material was chosen flat spring steel with a tensile strength $\mathrm{R}_{\mathrm{m}}>1500 \mathrm{MPa}$. The surface should be without high roughness. A deep rolling process is a good way.

\subsection{Description of the sample}

Here is the sample described which the author made for the round robin test and afterwards for his one lab. After making the second calibration sample it was matched with the sample out of the round robin test.

One millimeter of the sample surface was grinded to remove possible decarburization. Afterwards an area of $55 \mathrm{~mm}$ * $55 \mathrm{~mm}$ was deep rolled in a meandering pattern like shown in figure. 2.

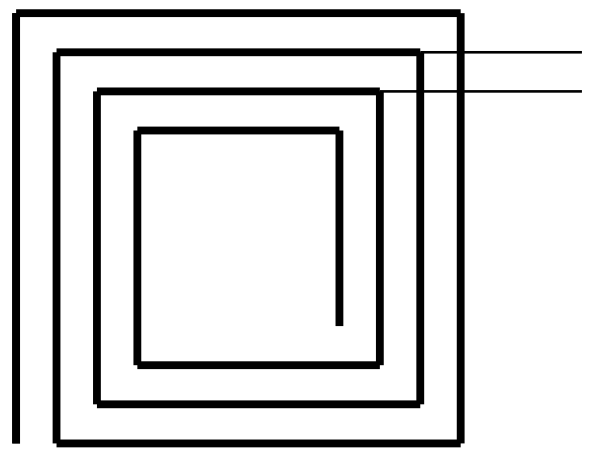

$\Delta \mathrm{X}$

Fig. 2: track pattern of the sample

Two samples were deep rolled with an HG6-tool (from the company Ecoroll in Germany). The track distance $\Delta \mathrm{x}$ was optimized to $\Delta \mathrm{x}=0.15 \mathrm{~mm}$. The ball diameter was $6 \mathrm{~mm}$ and of amount of pressure on the ball was $100 \mathrm{bar}$.[15]. The roughness $\mathrm{R}_{\mathrm{z}}$ is between 5 and $12 \mu \mathrm{m}$. Perpendicular to the rolling tracks you get a compressive residual stresses $\sigma$ of nearly $\sigma=2 / 3 * \mathrm{R}_{\mathrm{m}}$ (tensile strength), which means more than $900 \mathrm{MPa}$.

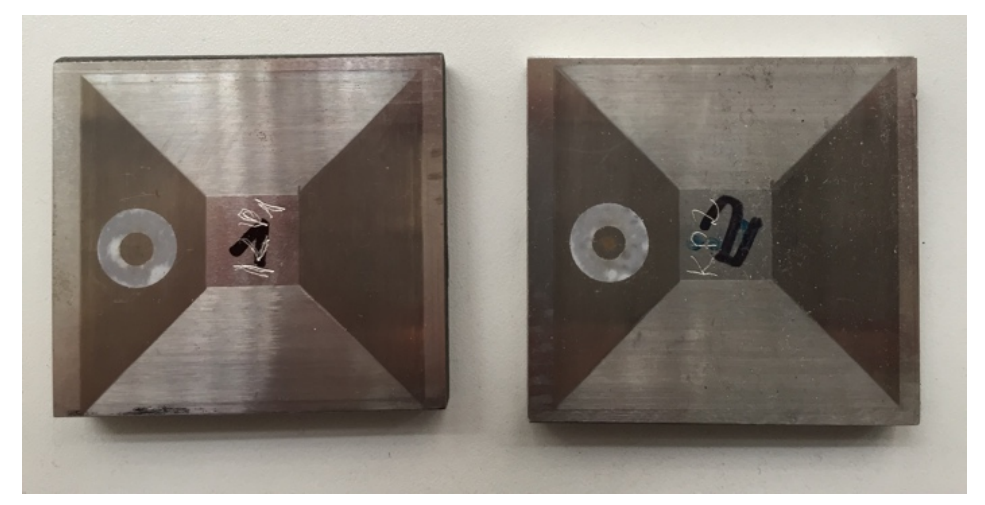

Fig. 3: practical realization of the two sample with the measuring spot

The great round robin test where organized by Mr Lietzau (company GKN in Germany). The sample, made by the author, was measured in around 30 different labs in less than two years. The sample has as a result a compressive residual stress of $\sigma=-1120 \mathrm{MPa}+/-43 \mathrm{MPa}$ [14]. The two samples were deduced of this main sample. The residual stress of $\sigma=$ $-925 \mathrm{MPa}$ and $-932 \mathrm{MPa}$ was achieved with nearly the same absolute error. These samples can be used to calibrate x-ray measuring equipment [16].

\section{Conclusions}

In the moment not standard for determine residual stresses is not available. An uncertainty of $5 \%$ is today the systematic error of a calibrated x-ray diffractometer to determine residual stresses. Most of the labs can only make a zeropoint calibration [17] and a long-term stability check.

Many specifications of companies claim small errors (1\%). They do not take the systematic error in consideration. But an statistical error of less than $2 \%$ or $3 \%$ does not affect the total error significantly. 
I thank Mr. Lietzau of GKN for his great efforts to organize and evaluate this big round robin test. Permanently he is working to improve the uncertainties of the calibration x-ray measuring equipment.

\section{References}

1. I. C. Noyan, J. B. Cohen: Residual Stress, Springer Verlag, New York, (1987)

2. SAE-Paper: Residual Stress Measurements by X-Ray Diffraction, No.: SAE J784a, Warrendale, (1971)

3. B. B. He: Two-Dimensional X-Ray Diffraction, Wiley, New Jersey (2009)

4. J. Ramirez-Rico, , S. Y. Lee., J. J. Ling, I. Noyan, C.. Stress measurement using area detectors: a theoretical and experimental comparison of different methods in ferritic steel using a portable X-ray apparatus. Journal of Materials Science, 51(11) (2016), pp.5343-5355.

5. D. Delbergue, D. Texter, M. Levesque, p. Bocher: Comparison of Two X-Ray Residual Stress Measurement Methods: $\operatorname{Sin}^{2} \psi$ and $\operatorname{Cos} \alpha$, Through the Determination of a Martensitic Steel X-Ray Elastic Constant. Materials Research Proceedings, 2 (2016), pp 55-60

6. E. Müller: Röntgenografische Eigenspannungs-messungen -Vergleich zweier Methoden-. Deutscher Verband für Materialforschung -prüfung e. V., Berlin (2017), pp. 147-150

7. E. Müller: Messung von Lastspannungen bei verschiedenen Oberflächenrauhigkeiten mit Hilfe eines Röntgendiffraktometers, HTM 48 (1993) 1/93, pp. 50 - 52.

8. E. Müller: The Difficulty of Measuring the Residual Stress at Shot Peened Surfaces, MFN (Metal Finishing News), Vol.11, Nov. 2010, pp. $60-61$

9. E. Müller: How Precise can be the Residual Stress Determined by X-Ray Diffraction? A summary of the Possibilities and Limits. Materials Research Proceedings, 2 (2016), pp. 295 - 298

10. DIN EN 15305:2009-04: Non-destructive testing - Test method for residual stress analysis by X-ray diffraction, Berlin (2009)

11. J. Lietzau: Ringversuch Eigenspannungen, presentation given at the Sitzung des AWT FA13 „Eigenspannungen“, Freiburg, (Germany) 29.04.2008

12. R. Yokohama: X-ray Residual Stress Evaluation of Springs, Rigaku Cooperation, presentation given in Donnguan (China), June 2013

13. E. Müller: Ringversuch - Eigenspannungen, Verband der deutschen Federnindustrie, presentation given at the Jahreshauptversammlung, Leipzig (Germany), May 2014

14. J. Lietzau: Materials Engineering Report No. 18_L13167, released 22 Oct. 2014, GKN Driveline Int. GmbH, Lohmar, (2014)

15. E. Müller: Evolution of the residual stresses by stress rolling, IITT-International, Noisy-le-Grand (2005) pp. 436 441.

16. E. Müller: Die Messung von Eigenspannungen mittels Röntgendiffraktion und die Sinnhaftigkeit der Fehlernangabe, Fortschritte in der Werkstoff-prüfung für Forschung und Praxis, Verlag Stahleisen, Düsseldorf, (2015), pp. 215 - 219

17. S. Yasukawa, T. Miyoshi, M.Yamamoto, T. Yamamoto, S. Ohya, S.: Standard Sample Package for Calibration of XRay Stress Measurement. Materials Science Forum, Vol. 768 (2014), pp. 242 -245. 